\title{
Some reflections on a global strategic culture issue
}

\author{
Oleg N. Yanitsky \\ Doctor of Philosophy, Professor, Chief Researcher, \\ The Federal Center of Theoretical and Applied Sociology \\ of the Russian academy of sciences.
}

\begin{abstract}
Drawing on the works of leading European and Russian scientists and scholars of the XX-XXI centuries, on the results of many international and national research projects as well as on my own investigations in such interdisciplinary realm as social ecology of the large cities of the world and social ecology in the digital age, I came to the following conclusions. The global strategic culture is a product of the New Times when the people began to realize that our planet is spherical not only as a natural organism but a social one as well. It meant that Europe as social organism has a space for its further expansion and enrichment into the virgin lands. The reverse side of the same coin has been confirmed by of atomic nucleus fission that showed the principled relativity of such notion as a 'big' and 'small.' A key role in the shaping of a global strategic culture has been played by scientific and technological progress on the edge of the XX and XXI centuries, technologically developed and tested between and just after the WWI and WWII and confirmed by the testing of nuclear arms in the mid1940s. The essence of my concept of global strategic culture is its all-embracing and all-penetrating character coupled with a permanently speeding up its time-space parameters. I interpret the global strategic culture as a mean of survival of humanity together with his living environment and consider these features as the key distinguishing features of this cultural archetype. These features differs this archetype from all other cultural archetypes that have been characterized by a small set of very stable (unchangeable) signs.
\end{abstract}

Keywords: archetypes, digitalization, education, globalization, integration, interdisciplinary approach, science, scientific community, strategic culture, transition period

\section{HISTORICAL ROOTS AND DEFINITIONS OF THE NOTION}

The very notion of the strategic culture had been offered by J. Schneider in the 1977 and developed by A. Jonson in the 1995. In short, the American strategic culture is a combination of its socio-political and military cultures. In a more narrow sense this culture defines the key principles of the US global military politics and principles vs. the Russian strategic policy of defense (Carnes, 1985; Kokoshin, 2003; Korotaev et al., 2012; Alexeeva, 2012).

The majority of the authors interpret this term as the culture of a struggle and survival of one or another social actor (the state, their alliance, a certain transnationals) at the expense of all other actors and their living environment. My aim is quite another. Not underestimating a significance of this notion for the theory of local and global wars developed by military scientists, I prefer to consider the global strategic culture as a mean of a survival of humanity together with his living environment. In other words, I'm trying to develop a humanistic concept of this global culture.

Developing this concept I relied upon a number of the concepts and publications which have different but interrelated views of the globalization process and its human and other consequences (Bauman, 2001, 2004, 2017; Beck, 1999; Castells, 1996, 2004; Beck at al., 1994; Forrester, 1971; Mosbah-Natanson and Gingras, 2014; Therborn, 2000; Urry, 2007). 
Under global strategic culture I mean here a system of the principles, values and norms of a certain actor securing simultaneously his development, sustainability and self-protection under permanently change of geopolitical conditions. Such culture is inherent to the actor of any scaly if he/she is capable to fulfil the above requirements. To be inherently sustainable (but not unmovable) in our uncertain and quickly developing world is a distinguishing feature of any living organism, be it natural or social one.

The very fact of an existence of the strategic culture of a certain actor doesn't exclude a possibility of its sharp change provoked, for example, by a sudden growth of international tension, disaster or inner conflicts and decay. That is the above double-sided changes are the indispensable qualities of strategic culture.

My concept of the strategic culture is based on the relationships between the past, present and future of global community as a whole but these relationships are flexible: the further the more the present and future begins to dominate over the past. Therefore, the long-term historical and futurologist studies are the indispensable parts of shaping of the global strategic culture concept. A capability to count a right proportion between the past, present and future is a rather important quality of any actor.

A simultaneous development of a global community and its inner transformations including a wastes production is its norm only when this double cycle (the development and decay) makes minimum harm to humanity and its socio-biotechnical living environment (Yanitsky, 2016).

It means that global strategic culture should rely upon both on a minimal use of natural resources and maximal recycling of the wastes. These requirements may be reached only when humanity activity will be based on self-limited consumption of its development and thrifty use of recycled products. In particular it means that a production of the means of a warship (arms, explosives, etc.) has to be reduced to a level necessary for the maintenance of global safety.

\section{WHO IS A PRODUCER OF GLOBAL STRATEGIC CULTURE?}

It's a not an easy question. For the first glance, it's the global community as a whole that gradually converts a myriad of economic, social, cultural and natural impulses into abovementioned system of the principles, values and norms. But actually it's a rough description of the process how human history is gradually reworking these facts and impulses into the culture, but into a which one? The accumulated archives materials had been reworked into the culture of the past times by the historians and the other scientists. It means that such natural-historical approach is not fit to a structure and a pace of development of global reality, and in particular to its diversified Brownian movement.

A more realistic picture is the struggle between various archetypes of local and global culture when some of them are already exists as national or regional cultures while the others are only in the phase of shaping, still others are forcefully imposed onto the global whole. Recently, a market is the most powerful culture of the world. But strategically, the market is a one-sided strategic culture which has a mighty mechanism of its self-development at the expense of repression of all other cultures or converting them into subaltern mechanisms of global market economy. In any case, modern market culture isn't capable to protect and maintain all other cultures of the world. The 'Making money' or the 'Time is money' and other similar slogans of market economy are not only the slogans as such but they are media-representatives of $a$ deep culture of modern capitalism as a well-institutionalized collective subject. 
This fact signifies that somewhere should be a counterbalance to that expansionist attitude of market economy culture. Superficially, it's the state and the transnationals. But it's again wrong because they are the main carriers and defenders of the above capitalist culture. At the same time, following U. Beck we realize that in that very case the strategic culture appears as a sideeffect of already happened processes, changes and disasters.

Does this challenge the utopia or wishful thinking? I'm convinced that isn't because the strategic culture which simultaneously combines a global community development, its sustainability and self-protection under permanently changing conditions cannot be constructed artificially. Such challenge has to emerge as an urgent need of a global community balancing on the edge of the abyss. But it's not efficient way out. What's then?

I'm not the economist but as some respected economists stated, a gross profit of the world economy is gradually decreased, and the recession and then long-term economic crisis will come. From the viewpoint of both the sociologists and geopolitics, such negative trend is inevitably leading to mass social and political protests. I foresee that it will be not national or regional social-economic crisis but an all-embracing critical situation which couldn't be effaced by a political means only (Yanitsky, 2014).

\section{THE ARCHETYPES OF THE GLOBAL STRATEGIC CULTURE}

It's the most difficult point of the issue under consideration but it cannot be missed. It seems to me that there are at least four such archetypes. I'd like to remind that it is going on not about already historically shaped archetypes but concerning some ideally-constructed archetypes of modern global culture. Besides, the very term 'global culture' doesn't mean that the current globalization process has already embraced all social and natural units across the world. I consider the globalization and all other processes in question as the dominating trends and principles of the world institutional structure only that doesn't exclude other familiar or countervailing trends. On the other hand, these archetypes are shaping in the process of struggle with other principles and institutions of global social order.

To my mind, there are at least four such archetypes of global strategic culture.

The first one I've named as the imperialistic or conquistador one. Such global strategic culture is based on the principle of economic and geopolitical supremacy of one social subject over all others social and natural entities. The adherents of such archetype are deeply convinced that the resources in which they are needed for the maintenance of their total supremacy are always at hands because they may be reached at the expense of any other unit of global whole. Practically and culturally it means that there are no any resource limits for their unlimited development.

That is, this archetype is relied upon the maxima of its unlimited economic, social and spatial expansion. In other words, it's a clear hierarchical model of global strategic culture. Our world is now at the very hot point of a tough struggle of the subjects that are the adherents of such viewpoint with all others. As history clearly showed, this conquistador archetype has periodically emerged in human history but then have shrunk and disappeared.

The second archetype I've called as balanced one. Actually, it's a version of global democratic order, the principle which has been proclaimed many times before but never practically realized in full. Under the balance I mean the balance of interests and needs of all natural and social units populated the world. The balance principle means the understanding the 
humanity's access to resources that are needed to its reproduction is always limited. This principle is implied a necessity for self-restriction of wills and needs of human beings.

Then, the balanced principle means an interdependence of all its inert and living actors. Finally and the most importantly, the balanced approach implies the understanding of our life-sphere as a very complex and mobile sociobiotechnical system. This principle doesn't mean that all structural-functional elements of the global whole are well-balanced. To live in and to maintain balanced natural and social environment are the necessary prerequisites of human existence and development. It's clear that every well-balanced process is relied upon the knowledge of its limits and on the dialogue concerning of how to gain the results that would satisfy all the parties involved.

The third archetype I'm calling as a cooperative one. Its distinguishing feature is to resolve the key global issues collectively in the run of the processes of a permanent dialogue between the interest groups, the transnationals, the states and their economic and political alliances. It means that though the parties involved in such dialogues have their particular interests, they clearly realized that the dialogue is much better than any confrontation or a hybrid war, and the expenses for this kind of activity will be much greater than any peaceful resolving of a particular global or regional issue.

The participation in such dialogues and cooperation of a business, powers structures and civil organizations is an indispensable prerequisite of a fruitful cooperation of the above subjects and political activity. I'd stress the difference between the discourse and dialogue. The former signifies only the fact of mutual interest of the parties involved while the latter presupposes the existence of a mutual aims of its practical resolving that would satisfy both sides. It's well understandable that it's going on about the dialogue of the business, power structures, civil society organizations and a concerned layer of population. Such archetype may be named as a 'horizontal one.'

The fourth archetype of the strategic culture I'm calling as a humanistic one. It's not going on the human solidarity only as P. Sorokin stated. The issue in question is much more deep and complex. Three abovementioned concepts of the global strategic culture are overtly presuppose the existence of the market mode of production and reproduction of social life. The humanistic concept of strategic culture isn't totally neglect the principle of competition in the nature and social whole but in the final analysis it relies upon not on struggle of survival principle but on the priority of humanistic approach to man and nature equally.

It means that this particular archetype of the strategic culture is based on the principle of complex and inseparable a man-environmental structures, from local to global, natural or socially-constructed which in turn is relied upon a mutual interdependence of natural, social and man-made parts of any modern environments. It means that this archetype of the strategic culture is grounded on a principle of socio-biotechnical metabolic processes between all natural, social and artificial organisms. It may seem paradoxically, but this humanistic archetype of strategic culture is relied upon the formulae 'all interconnected with all, and all is going somewhere', the principle formulated by the US biologist and ecologist Barry Commoner. As to solidarity activity, in the case of humanistic culture it means the mutual interdependence and exchange of matter and energy between all actors involved including their environment, be it natural, social or complex i.e. socially-constructed. 


\section{THE ROLE OF SCIENCE AND SCIENTIFIC COMMUNITIES}

As it more or less clear, the role of them in the processes of shaping the above archetypes is very important but quite different in the abovementioned archetypes of strategic culture.

In the case of the conquistador global strategic culture the scientific knowledge and its institutions are the servants of this very aggressive type of culture. Unfortunately, for the reason of participation in the market relationships we in one way or another are becoming the hostages of such aggressive global culture. The struggle for an access to necessary resources and for the safety of a social community or the state forced us to spent giant money and intellectual efforts for arms production and military operations. Any strategic culture isn't a mechanical set of cultural and institution instruments but a tightly interdependent whole of values, aims, social and man-made instruments and the institutions. Of course, when the technological innovations became widespread they are turning into consumer goods. But even in this 'peaceful' field the battles are going every day.

As to the case of so-called 'balanced strategic culture', its inner balance is still maintained occasionally and partly but violated very regularly. It happens because the very market world is based on the principles of rigid competition often without any rules. Therefore, this very archetype of strategic culture is in a great degree maintained by the struggle without any common rules accepted by the United Nations and other respectable international organizations. That is why as in the previous case the scientific knowledge and its institutions are playing the role of the servants of this double-decked type of culture. And the scientific, technological and social inventions fulfill the same role as in the case of conquistador strategic culture maintenance. From my viewpoint, until now the 'balanced strategic culture' is still a wishful thinking and not the cultural values and norms shared by the overwhelming majority of the United Nations. An international principle of the 'sustainable development' constructed and widely accepted even in the 1980s still remained a slogan and not a founding principle of international relationships.

In contrast to previous case the cooperation of the scientists, scientific groups and institutions is a widespread method and instrument of the cooperative strategic culture. It's a wellunderstandable phenomenon because the global stakeholders began to realize that scientific cooperation allows to them to save time and resources and thus assists to win in global races for resources, markets and geopolitical domination. But once again, it's a partial or ad hoc cooperation having nothing in common with the cooperation of the scientists and scholars of the world in the name to maintain of the sustainable peace on the whole planet.

At the same time it should be underscored that modern hybrid wars gave a mighty impetus to the cooperation of natural, social and technical scientists. But once again, it's going on about the cooperation aimed at resolving particular geopolitical, social and technological problems but not for the cooperation of all global forces beyond political borders to save our planet and the humanity. We have to return to the mid1950s when a group of outstanding scientists across the world had established well-known the Pugwash movement of concerned scientists for a peace and security.

The role of scientists and global scientific community in the shaping of the humanistic type of global strategic culture is the most disputable one. On the one hand, it seems quite naturally if a 'consortium' of natural, social and technical sciences would make their contribution in the shaping of this type of strategic culture. On the other hand, it has to be a coordinated i.e. inherently concerted input otherwise we'll get a chaotic action, no more. 
Here we again encounter with mutual mistrust of the representatives of abovementioned three types of knowledge because for centuries they have been developing separately conceptually and institutionally. It signifies that before speculating concerning the role of scientific knowledge in the shaping of humanistic archetype of global strategic culture we should to overcome the above inter-sciences borders. Besides, nobody knows what particular language it should be in order to translate this integrated scientific knowledge in the terms of humanism and wellbeing of a very complex organism named our planet. All said above forced me to state that from this i.e. scientific viewpoint, the humanistic type of global strategic culture is still no more than the wishful mode of theorizing, at least nowadays. In two following paragraphs I'll try to substantiate this statement in a more details.

\section{WHAT HAS BEEN MISSED?}

First, the fact that the above four archetypes of strategic culture are exists only on the paper. Saying this I don't reject their methodological and theoretical value of them but they are now a certain ideal types only. To be converted into efficient theoretical instrument the above four archetypes should be empirically tested.

Second, there is a substantial difference between a particular theoretical construction and its transformation into an actual force that is capable to influence social processes or institutional structures.

Third, the theorists have to take into account at least three interrelated processes: (1) the interactions and mutual transformations of the above archetypes; (2) their interrelations with the other natural and social actors, and (3) a feedback of changing environment on the above archetypes.

Fourth, the theorists are usually underestimated that any 'environment' is also the actor which is able to seriously modify each of the above archetypes of global strategic culture. As it will be shown, in some cases the four above archetypes of strategic culture will work while in the others the only one will remain as a factor of ongoing changes.

Fifth, as we already know, recently is the time of hybridization of all with all because the hybridization is the most efficient instrument in the struggle for self-protection, gaining of vitally necessary resources and geopolitical domination.

Sixth and the most important, is the transformations generated by the process of a Digital Revolution. These transformations are so substantial and all-embracing that they deserve special attention.

\section{GLOBAL CULTURAL ARCHETYPES IN THE DIGITAL AGE}

First, recently we have a right to confirm that globalization as a state of the world is allembracing and all-penetrating one, at least from the formal viewpoint that is each inhabitant of global community has an access to the global network system. It in turn means that a certain global culture already exists across the world.

Second, an information-communication network serves as material basis of it. This basis is not 'neutral' to any social entity which this network embraces. On the contrary, this network is an inseparable part of a new mode of production that has many differences from the Industrial mode of production. 
Thirdly, this new mode of production is much less tied up with the spatial structure than the previous ones. The information-communication network is the living space as the territorial communities and societies of the past.

Fourthly, thus now every inhabitant of our planet is simultaneously living in two spaces, the material i.e. territorial and informational ones. This situation is a radically another in comparison with all other forms of human settlements. In particular, it means that every inhabitant potentially may be both a member of global human community and many local communities. At the same time it signifies that these inhabitants much less tied up with a particular territory or human community.

Fifthly, simultaneously it means that such 'information equality' is only formal one. On the contrary, the Fourth industrial revolution generates a set of new inequalities. For example, an exclusion from this global informational network might mean a total exclusion form a global community life.

Sixthly, the living in two spaces is Janus like phenomenon. On the one hand, it means the weakening ties with any local groups and communities. On the other hand, it means a rapid shaping an entirely new living space, a virtual one which very soon acquires an institutional status as social networks, forums, chats and many other virtual constants or temporary forms of human communities.

Seventhly, a mass-media as a social institution is becoming an instrument for a shaping of mass consciousness and a government of human behavior. As a result, the rank-and-file people are becoming uprooted from their native milieu i.e. from their Motherlands and governed by the giant media corporations.

Eighthly, the phenomenon called the 'weakness is the power' has emerged. It means that the behavior and relationships of the actor of any size may be directed and governed by the only one man or by the press of a button generating the harmful and all-penetrating disasters.

Ninthly, a time in all respects (time of production, delivery, hacker's attack or of comprehension of what is going on, etc.) is becoming a key factor of all kinds of local-global struggle for gaining necessary resources and/or geopolitical domination. The pace of ongoing events not only fastening every moment but it's difficult to define the difference between the true and false information. As a result, a hybridization of information flow is becoming a mighty arm in the struggle with possible adversary.

Tenthly, all said above signifies that an existed institutional structure of a global social community has to be seriously transformed. In particular it first of all means that this structure has to be prepared to respond to a flow of challenges permanently produced by the Fourth industrial revolution.

Eleventh, but step by step this revolution will shape the new mode of production, the information-communication one that is now replacing the previous one. It's a very important transition period which will be briefly described and analyzed in the following section.

Twelfth, a digitalization process embraces entirely all spheres of natural and social life. It leads me to the statement that a new type of global strategic culture is emerging. Theoretically speaking, such culture has to be of universalistic character that is to be simultaneously local 
and global, a transcontinental and acceptable to all nation states and local communities, adapted to any particular natural and social milieu and so on and so forth.

Finally it means that the earth population should master a very specific digital language which is now understandable to a part of the global IT and business community only. But if we attempt to simplify this language we'll see that it's based on the well-known common principles: maximum speed and safety, a quick reply to the changes and demands of our respondents or the need of global Internet market and a set of other well-known principles of communication under market economy.

\section{SOME CHARACTERISTICS OF THE TRANSITION PERIOD}

Transition period towards what, it's not an easy question because the starting points of various countries and communities are different. Besides, there are some other factors which are capable to influence the transition period. Therefore, I'll set them again down point by point.

First, the modern global strategic culture has to be a systemic one that is to take into account an integrated character of the world. Under the notion 'world' I mean its socio-biotechnical nature. That is this culture should comprehend various metabolic processes within it and between it and the space. How these factors will transform the essence of global culture it's now hard to foresee. For example, the modern astrophysics predicts that the further the more the sun radiation will become more rigid and this only one factor may seriously change forms of life of all living organisms (Atri and Melot, 2014).

Second, in time the natural resources like the drinking water, gas-and-oil, forests as well as the squares for the foodstuff production will diminished or totally exhausted, and the struggle for deficit resources will grow. In this respect Russia, on the one hand, has undoubted priorities but from the other hand, has to defend its natural wealth. So that Russian strategic culture has to be more defensive.

Thirdly, every transition period is a certain time 'in-between.' The existing institutions are not fit to an uncertain and rapidly changing situation whereas the new ones are only in the stage of design or testing. Since there is no 'empty spaces' in global social relationships this gap has to be covered by short-term plans and decisions, making roadmaps and the like. That is global sustainability is composed from an activity of many local and regional pro and contra forces.

Fourthly, from the viewpoint of sociology and political sciences the coming transition period is burdened by growing social tension, reducing of labor market, misunderstanding between the young and old, etc. Social uncertainty is of no less disturbing as the uncertainty of the weather and unintended geopolitical events and moves.

Fifthly, the problem of permanent education deserves a special attention. As M. Castells rightly stated a new technological divide is emerging. The 'Internet-based learning is not only a matter of technological proficiency: it changes the kind of education that is required both to work on the Internet and to develop learning ability in the Internet-based economy and society. The critical matter is to shift from learning to learning-to-learn, as most information is on-line, and what is really required is the skill to decide what to work for, how to retrieve it, how to process it, and how to use it for the specific task that prompted the search of information' (Castells, 2004: 258-259). All is correct but these requirements don't differ from those which have been developed in the times of the Enlightenments. 
In addition, let me remind that in the accordance with the law of Bredford and Zipf, the only half of required information is concentrated in professional journals whereas the other part is disseminated in a myriad of other off-line and online editions and sources.

Is it all said above will put forward the principle of sustainability as a key feature of the transition period? To my mind, the answer will be yes and no. 'Yes', because the global community is now balancing on the edge of the abyss of a total nuclear war. 'No', because there are many other factors which define this period, and fist of all it's the global warming accompanied by very unsettled weather and its inevitable associates like the forest fires, floods, tornados, etc. Anyhow it means that the further the more the global strategic culture has to be more flexible responding to permanently changing social and weather conditions. In such situation the very term of sustainability acquires quite another sense, namely to be sustainable is to be able to respond to many inner and outer challenges simultaneously.

\section{DIVIDING THE FUNCTIONS BETWEEN A SOCIETY AND INDIVIDUAL}

The starting point of discussion on the above issue is a predictability of coming transformations and the overcoming the existing state of affairs that is the living in a society of the side-effects (Beck, 1999). The predictability of the global future totally depends on a future mode of production and social reproduction. If it will be the same market economy with its all abovementioned aims and geopolitical strategies nothing would change.

So it means that global social institutions have to be subjected to serious transformations. In what particular direction they have to move? In the directions conditioned by already mentioned ultimate goals as the protection and maintenance of our planet as living sociobiotechnical organism. These two fundamental goals came to the forefront. The methods and structures of the reach and maintenance of such ultimate goals are beyond the frames of this article. I haven't now the arguments except referring to the history of our planet. It shows that the only one way out of global critical situation is a strict economy of all kind of living resources including spatial mobility. To my mind, such slowdown of the tempo-rhythms of global development will have a positive natural and social effect.

Another possible instrument for the achievement of the above goals is an interdisciplinary approach and accordingly a coordination of activity and its tempo-rhythms of recently institutionally divided global social institutions.

All said above is related to the individuals' mode of living and their life-stories. Nowadays, the individual is involved in a permanently accelerating of a 'flow' of life events. He has no time neither to be prepared to such constant acceleration nor the instruments for the protection from it. Then, as Bauman argued, during the modern era 'managerial strategies were focused on rendering behavior of their subordinates utterly predetermined and therefore predictable through eliminating or suppressing all and any factors of influence other than the commands issues by the superiors...' The 'new managerial strategy is the shifting of responsibility for the results onto the shoulders of the managed, simultaneously reducing the responsibility of the managers to the selection of the managed according to the promise of profitability their hold for the enterprise...' (Bauman, 2017: 114, 116).

The other side of the same coin is the mass processes of a self-undressing. As Bauman rightly noted, 'Millions of Facebook users vie with each other to disclose and put on public record the most intimate and otherwise inaccessible aspects of their identity, social connections, thoughts, feelings and activities. Social websites are fields of a voluntary, do-it-yourself form of 
surveillance, beating hands down (both volume-wise and expenditure-wise) the specialist agencies manned by professionals of spying and detection.' (Bauman, 2017: 79-80).

Such new pressure is accompanied by the speeding up of changes in all spheres of natural and social life that should be comprehended and taken into account in the everyday life of all types and ranks of the employees. Such permanently speeding up of everyday tempo-rhythms has many negative side-effects as a low quality of work, psychological tension, social conflicts, harm to a living environment and so on. The said above is one more reason to replace human labor by the smart machines. In sum, an endless acceleration of all living processes of global community is inevitably leading to the replacement of a man by a machine.

\section{CONCLUSION}

In the final analysis, despite all social and technological innovations our planet as inhabited space is a finite one, and not only for the reason of population and economic growth as the authors of 'The Limits to Growth' fifty years project have predicted many times (Von Weizsäcker and Wijkman, 2018).

Summing up, I see the following features of the global strategic culture. Recently this culture is the all-embracing and all-penetrating culture which is necessary for global human community survival as an air, water, energy and other natural and human resources.

The production, processing, storage and disseminating of a scientific knowledge are the driving forces and the key resources of the production of global strategic culture in the digital age. It means that one has a right to consider that global system as a specific social institution of this age.

In the digital age the scientific knowledge is becoming a major capital of modern society but for the conversion it into a driving force and the strategic culture creation and maintenance a financial capital and many other social institutions are needed.

It follows that that the strategic culture of the digital age is the product of the functioning of this very complicated and contradictory global social 'machine' that is burdened with the tough struggle of numerous social and natural actors. It's very important that this global culture isn't simply exists as a certain supreme norm but permanently reproduced and changed in the run of the struggle of numerous social agents.

Thus, there is a principled difference between the current 'mobile' global strategic culture and the previous ones. The only one openly seen distinguishing feature of global strategic culture is a replacement of physical labor of a man and machine by the work of a man-smart machine technological hybrid.

Due to the use of such hybrid technologies humanity, consciously and unconsciously, is permanently speeding up the processes of thinking, designing, constructing and realizing of the adopted decisions. Such 'compression of time' which isn't peculiar to natural species is becoming a key precondition of global strategic culture of humans.

The individuals are becoming more and more dependent on the accelerating transformations of information-communication networks. It's indicative that becoming placeless these individuals are looking for other people and by means of they totally disclose their identity to the entire world including for all those who may manipulate them or supply with a false 
information. An interesting opposition has emerged: a closed system of information produced by mega-structures vs. totally-opened individual as producer of intimate information.

But such speeding of human life has its own limits conditioned by a natural habit of human organism. There are two ways out: either to totally replace humanity as a biological species by a 'society' of the smart machines or to gradually slow down these 'digital races' of man-smart machine hybrids. Otherwise, a society of the smart machines will take over. But now $a$ permanently speeding up time-space parameters of current global culture is one of the distinguishing features of this cultural archetype. This feature differ this archetype from all other cultural archetypes that have been characterized by a small set of stable (unchangeable) rules and norms.

In the near future we'll see a division of global strategic culture in two qualitatively different cultures. The former will reflect the will of humanity to survival here, on the earth while the latter will be concentrated on construction the technologies allowed to the minority of humanity to resettle to another planet.

\section{References}

Alexeeva T. 2012. Strategical Culture. Polis, No 5: 56-62 (in Russ.).

Atri D., Melot A. 2014. Cosmic Rays and Terrestrial Life: A Brief Review. Astro-particle Physics, Vol. 53: 186-190.

Carnes L. 1985. American Strategic Culture. Comparative Sociology, Vol. 5, No 3: 269-291.

Bauman Z. 2001. On Glocalization: Or Globalization for some, localization for some others, in: Bauman Z. The Bauman reader. Malden, MA: Blackwell Publishers Inc.: 298-311.

Bauman Z. 2004. Wasted Lives. Modernity and its Outcasts. Cambridge, UK: Polity Press. 140 pp.

Bauman Z. 2017. A Chronicle of Crisis: 2011-2016. London, UK: Social Europe Edition. 163 pp.

Beck U. 1999. World Risk Society. Malden, MA: Polity Press. 184 pp.

Beck U., Giddens A., Lash S. 1994. Reflexive Modernization. Politics, Tradition and Aesthetics in the Modern Social Order. Stanford, CA: Stanford University Press.

Castells M. 1996. The Information Age. Economy, Society and Culture. Oxford: Blackwell Publishers, Ltd.

Castells M. 2004. The Internet Galaxy. Reflections on the Internet, Business, and Society. Oxford: Oxford University Press.

Forrester J.W. 1971. World Dynamics. Cambridge: Wright-Allen Press.

Kokoshin A. 2003. Strategy of Government: The Theory, Historical experience, Comparative Analysis, and the Tasks for Russia. Moscow: ROSSPEN. (In Russ.).

Korotaev A., Zin'kina A., Chodunov A., eds. 2012. System Monitoring of Global and Regional Risks. Arabian Spring of the 2011. Moscow: LKI Publishing House. (In Russ.).

Mosbah-Natanson S. and Gingras Y. 2014. The Globalization of social sciences? Evidence from a quantitative analysis of 30 years of production, collaboration and citations in the social sciences (1980-2009). Current Sociology, Vol 62 (5): 626-646.

Therborn J. 2000. Three concepts of globalization. International Sociology, Vo. 15 (2): 180-196.

Von Weizsäcker E. and Wijkman A. 2018. Come On! Capitalism, Short-termism, Population, and the Destruction of the Planet. Springer. DOI 10.1007/978-1-4939-7419-1

Yanitsky 0. 2014. Sociology of Critical Areas. Open Journal of Social Science Research. 2014, Vol. 2 (3): 112-118. Available at: http://manuscript.sciknow.org/uploads/ojssr/pub/ojssr_140963345.pdf

Yanitsky O. 2016. Sotsiobiotechnical systems: A new view on man-nature relations. Sotsiologicheskaya nauka $i$ sotsial'naya praktika, Vol. 4, no 3: 5-22 (in Russ.).

Available at: http://manuscript.sciknow.org/uploads/ojssr/pub/ojssr_140963345.pdf 